\title{
Active mesopelagic prokaryotes support high respiration in the subtropical northeast Atlantic Ocean
}

\author{
Javier Arístegui \\ Departamento de Biología, Universidad de las Palmas de Gran Canaria, Las Palmas de Gran Canaria, Spain
}

Carlos M. Duarte

Instituto Mediterráneo de Estudios Avanzados (IMEDEA), Consejo Superior de Investigaciones Científicas-Universidad de las Islas Baleares (CSIC-UiB), Esporles, Spain

\section{Josep M. Gasol and Laura Alonso-Sáez \\ Departament de Biologia Marina i Oceanografia, Institut de Ciències del Mar-Centre Mediteranei d'Investigacions Marines i Ambientals (ICM-CMIMA), Consejo Superior de Investigaciones Científicas, Barcelona, Spain}

Received 28 October 2004; revised 23 December 2004; accepted 6 January 2005; published 11 February 2005.

[1] Here we provide evidence, based on prokaryote metabolic proxies and direct estimates of oxygen consumption, that the mesopelagic prokaryote assemblage in the subtropical Northeast Atlantic is an active one. It supports a high respiration $\left(0.22 \pm 0.05 \mu \mathrm{mol} \mathrm{O} \mathrm{I}^{-1} \mathrm{~d}^{-1}\right.$, corresponding to $68 \pm 8 \mathrm{mmol} \mathrm{CO}_{2} \mathrm{~m}^{-2} \mathrm{~d}^{-1}$ ), comparable to that of the epipelagic zone during the same period (64$97 \mathrm{mmol} \mathrm{C} \mathrm{m}^{-2} \mathrm{~d}^{-1}$ ). Our findings suggest that mesopelagic prokaryotes in the NE subtropical Ocean, as well as in other eastern boundary regions, are important carbon sinks for organic matter advected from the highly productive coastal systems, and would play a key role in the global carbon cycle of the oceans. Citation: Arístegui, J., C. M. Duarte, J. M. Gasol, and L. Alonso-Sáez (2005), Active mesopelagic prokaryotes support high respiration in the subtropical northeast Atlantic Ocean, Geophys. Res. Lett., 32, L03608, doi:10.1029/2004GL021863.

\section{Introduction}

[2] The mesopelagic (200-1000 m) open ocean has been suggested as a major site for biological oxygen consumption and $\mathrm{CO}_{2}$ production [del Giorgio and Duarte, 2002]. Yet, oxygen consumption in the mesopelagic zone has only been examined directly in a few regions, thereby precluding verification of the presumed role of its biota on the carbon budget of the ocean. The pioneering work of Jenkins in the Sargasso Sea [Jenkins, 1977] led for the first time to the estimation of oxygen consumption in the mesopelagic zone of the ocean, from changes in the apparent oxygen utilization (AOU) and the use of tracers to calculate the apparent age of a water mass. His results were surprising in that he showed that oxygen consumption in the mesopelagic zone of the Sargasso Sea was considerably higher than the estimates of new production in the same region [Jenkins, 1982]. Unfortunately, this biogeochemical approach is only useful for the few oceanic regions where mixing below the surface thermocline is assumed to be unimportant, and consequently the age of the water mass can be calculated with relative confidence. This handicap has impeded the

Copyright 2005 by the American Geophysical Union. 0094-8276/05/2004GL021863 derivation of global estimates of respiration in the dark ocean through AOU/tracers.

[3] The first assessment of global respiration in the dark ocean was recently produced by Aristegui et al. [2003]. These authors compiled available estimates of enzymatic ETS (electron transport system) respiratory activity in the dark ocean, and converted them to actual respiration rates $(\mathrm{R})$, by using a constant R/ETS ratio of 0.09 . The ratio was derived from empirical R/ETS relationships determined in vitro from monospecific cultures of bacteria at their senescent phase [Christensen et al., 1980], suggested to be representative of the dark ocean [Packard et al., 1988]. The calculated average global $\mathrm{R}$ in the dark ocean $\left(5 \mathrm{~mol} \mathrm{C} \mathrm{m}{ }^{-2} \mathrm{yr}^{-1}\right)$ was in close agreement with the oxygen utilization rates inferred from large-scale tracer balances by Jenkins for the Sargasso Sea, building confidence to the R/ETS calculations. However, Arístegui et al. [2003] cautioned about the uncertainty in the general use of a constant R/ETS ratio derived from bacteria cultures in a low-activity physiological state. Since, prokaryotic organisms in the deep ocean could maintain a rather high activity [e.g., Cho and Azam, 1988], the ETS to $\mathrm{R}$ conversion factor would need to be validated in each region through concomitant oxygen consumption and enzymatic measurements of natural mesopelagic communities.

[4] Here, we have addressed this challenge by combining direct measurements of in vitro oxygen consumption at selected depths and detailed vertical profiles of ETS determinations, in the mesopelagic zone of the subtropical Northeast Atlantic Ocean. Additionally, we examined different metabolic proxies for the degree of activity of the prokaryote assemblages in the mesopelagic zone, and compared them with the activity of surface-water assemblages. We aimed to test the hypothesis that eastern boundary regions, which are supposed to receive high lateral inputs of organic matter from coastal upwelling ecosystems, would maintain highly active mesopelagic microbial assemblages, supporting a high respiratory activity.

\section{Methods}

\subsection{Data Collection}

[5] The study was conducted along two zonal sections $\left(21^{\circ} \mathrm{N}\right.$ and $\left.26^{\circ} \mathrm{N}\right)$ extending from the NW African shelf to the open Atlantic Ocean at $26^{\circ} \mathrm{W}$, during May-June 2003. 
Table 1. Prokaryote Abundance and Activity in the Epipelagic and Mesopelagic Zones

\begin{tabular}{|c|c|c|c|c|c|}
\hline & \multicolumn{2}{|c|}{ Epipelagic Zone } & \multicolumn{2}{|c|}{ Mesopelagic Zone } & Ratio E:M \\
\hline Prokaryote abundance $\left(10^{8}\right.$ Cells $\left.1^{-1}\right)$ & 23 & $12.4 \pm 0.3$ & 31 & $1.8 \pm 0.2$ & 6.9 \\
\hline Leucine/Thymidine-based $\mathrm{P}$ (nmols $\mathrm{C}^{-1} \mathrm{~d}^{-1}$ ) & 27 & $391.6 \pm 77.1$ & 29 & $32.7 \pm 6.5$ & 12.4 \\
\hline Prokaryote $\mathrm{P} / \mathrm{B}\left(\mathrm{d}^{-1}\right)$ & 27 & $0.40 \pm 0.12$ & 29 & $0.13 \pm 0.02$ & 2.9 \\
\hline $\mathrm{CTC}+$ prokaryote abundance $\left(10^{7}\right.$ Cells $\left.1^{-1}\right)$ & 23 & $8.4 \pm 2.6$ & 20 & $1.7 \pm 0.3$ & 4.8 \\
\hline
\end{tabular}

A total of 10 , roughly equidistant, stations (5 in each section) were occupied. Samples for determination of prokaryote abundance and their physiological state were collected each $100 \mathrm{~m}$ down to $1000 \mathrm{~m}$. Samples for respiration experiments were obtained from $600 \mathrm{~m}(10 \pm$ $\left.0.1^{\circ} \mathrm{C}\right)$ and $1,000 \mathrm{~m}\left(6.7 \pm 0.1^{\circ} \mathrm{C}\right)$ depth, and immediately taken to chambers set at the in situ temperature $\left( \pm 0.2^{\circ} \mathrm{C}\right)$ conditions.

\subsection{Prokaryote Respiration (R)}

[6] Two approaches were used to estimate R: (1) Water samples drawn into carboys were siphoned into 5 replicate "time-zero" and "dark" (incubated for 2-4 days) $125 \mathrm{ml}$ BOD bottles. A time-series experiment was carried out at the most oceanic station; with 2 extra sets of "dark" replicate bottles added at intermediate times. $\mathrm{R}$ was estimated from the difference in oxygen concentration between the "zero" and "dark" bottles following incubation. Dissolved oxygen was measured by the Winkler technique, using an automated precise titration system, with colorimetric end-point detection. The mean standard error (SE) among replicated bottles was $0.08 \mu \mathrm{mol} \mathrm{O}_{2} \mathrm{l}^{-1}$. (2) Because R might often lie beyond the detection limit for the procedure described, $\mathrm{R}$ was also assessed by pre-concentrating (on-average, a factor of 2.2 fold) the prokaryote assemblage by inverse filtration under gentle pressure, using a temperature-controlled cell concentration chamber fitted with $76 \mathrm{~mm}, 0.1 \mu \mathrm{m}$ polycarbonate filters. The oxygen concentration was calculated spectrophotometrically, with a mean SE among replicated bottles of $0.43 \mu \mathrm{mol} \mathrm{O} \mathrm{O}_{2} \mathrm{1}^{-1}$ and a mean SE for replicated measurements from the same bottle of $0.19 \mu \mathrm{mol} \mathrm{O}_{2} \mathrm{l}^{-1}$. $\mathrm{R}$ was calculated as above. Additionally, we monitored changes in abundance and metabolism of the microbial assemblage during the incubations, allowing the backscaling of $\mathrm{R}$ to that corresponding to the assemblage prior to incubation (see results for details).

\subsection{ETS Measurements}

[7] Seawater (10 to $20 \mathrm{l}$ ), collected every $50 \mathrm{~m}$ from $200 \mathrm{~m}$ to $1000 \mathrm{~m}$ depth, was filtered through $47 \mathrm{~mm}$ Whatman GF/F filters, at a low vacuum pressure $(<0.3 \mathrm{~atm})$. The filters were stored in liquid nitrogen until being assayed in the laboratory. ETS determinations were carried out as described by Arístegui and Montero [1995]. An incubation time of $20 \mathrm{~min}$ at $18^{\circ} \mathrm{C}$ was used. ETS activities measured at $18^{\circ} \mathrm{C}$ were converted to activities at in situ temperatures by using the Arrhenius equation. A calculated activation energy of $16 \mathrm{kcal} \mathrm{mole}^{-1}$ was used.

\subsection{Prokaryote Abundance and Biomass}

[8] Cells were counted by flow cytometry, using a FACScalibur (Becton \& Dickinson) instrument [Gasol and del Giorgio, 2000]. Samples were fixed with $1 \%$ of paraformaldehyde $+0.05 \%$ glutaraldehyde (final concentrations) and stored deep-frozen until analyzed. Samples were stained with Syto13 (Molecular Probes Inc) at $2.5 \mu \mathrm{M}$ final concentration. Prokaryotes were detected by their signature in a plot of side scatter vs. green fluorescence. The division of total prokaryotes into high-NA and low-NA prokaryotes served both as an estimate of assemblage structure and of relative activity [Gasol and del Giorgio, 2000]. Green fluorescence was used as an estimate of prokaryote cell size [Gasol and del Giorgio, 2000] and converted to biomass using the alometric equation of Norland [1993].

\subsection{Prokaryote Physiological State}

[9] The CTC (5 cyano-2, 3 ditolyl tetrazolium chloride) reduction technique was used to estimate the physiological state of the prokaryote assemblages. We added $5 \mathrm{mM} \mathrm{CTC}$ of a daily-prepared batch to water samples that were incubated (from 3 to 12 hours) at in situ temperatures. After incubation, the samples were analyzed on board the ship with the cytometer, to measure the red fluorescence of the formazan granules and the relative size of each formazan particle.

\subsection{Prokaryote Production (P)}

[10] $\mathrm{P}$ was estimated from the incorporation of tritiated leucine (Leu) and thymidine (TdR), following standard procedures. We used 4 replicates plus two TCA-killed blanks and incubated with $40 \mathrm{nM}$ TdR and $40 \mathrm{nM}$ Leu for 3 to 8 hours. Precipitation was done with ice-cold TCA. Incorporation rates were transformed to carbon production rates with conversion factors of $1.5 \mathrm{~kg} \mathrm{C} \mathrm{mol} \mathrm{Leu}{ }^{-1}$, which assumes no intracellular isotope dilution, and $20 \mathrm{~kg} \mathrm{C}$ mol $\mathrm{TdR}^{-1}$, derived from a TdR conversion factor of $1.6 \times$ $10^{18}$ cells $\mathrm{mol}^{-1}$ and $13 \mathrm{fg} \mathrm{C}$ cell $^{-1}$. The average value of TdR and Leu production for each sample was used as the final $\mathrm{P}$ estimate.

\section{Results and Discussion}

[11] The abundance of prokaryotes in the mesopelagic zone of the subtropical NE Atlantic averaged $210^{8}$ cells $^{-1}$, with an average Leu and TdR-based production $(\mathrm{P})$ of

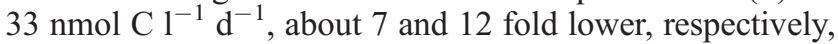
than in the epipelagic zone (Table 1). Highest $\mathrm{P}$ values were found in the area affected by the African coastal upwelling, while lower values were observed towards the central Atlantic. However, the average turnover of the mesopelagic prokaryote assemblage $\left(0.13 \pm 0.02 \mathrm{~d}^{-1}\right.$, Table 1$)$ was only 3 times less than that of the epipelagic prokaryotes, indicative of an actively growing mesopelagic assemblage. This was consistent with the relatively high contribution of prokaryotes with high-nucleic acid (NA) content to the 




Figure 1. Time-series experiments. Time variation of oxygen consumption, accumulated prokaryote production and biomass during a respiration experiment (average values $\pm \mathrm{SE}$ ), with an unconcentrated community sampled at $600 \mathrm{~m}$ depth from an oceanic station at $26^{\circ} \mathrm{N}, 26^{\circ} \mathrm{W}$.

assemblage $(58 \pm 2 \%$, Table 1$)$. Indeed, $8 \pm 1 \%$ of the mesopelagic prokaryotes were actively respiring, as indicated by their reduction of the tetrazolium salt CTC (Table 1), a fraction similar to that in the upper ocean $(7 \pm 1 \%)$. Furthermore, the respiring cells at mesopelagic depths produced $28 \%$ larger formazan granules than the surface prokaryotes (t-test, $\mathrm{P}<0.05)$, which suggests that the respiration rate per cell was higher in the mesopelagic zone.

[12] Prokaryote abundance increased upon confinement of the samples for respiration experiments with rates averaging $0.44 \pm 0.04 \mathrm{~d}^{-1}$ (average doubling time: 2.8 days). The 3 -days time-series experiment showed that the oxygen concentration decreased and the cumulative heterotrophic production increased gradually along the experiment (Figure 1). The integrated prokaryote respiration $\left(\mu \mathrm{mol} \mathrm{O}_{2} \mathrm{l}^{-1}\right)$ throughout all the experiments was closely related to the integrated prokaryote production ( $\mu$ mol $\mathrm{C}^{-1}$ ), measured both as the change in biomass $(\mathrm{r}=0.81, \mathrm{n}=30)$ and from the average Leu and TdR uptake $(\mathrm{r}=0.79, \mathrm{n}=30)$ (Figure 2). The measured daily rate of prokaryote respiration $(\mathrm{R})$ was also closely related to the average abundance of prokaryotes (PA), during each experiment (Figure 3), in spite that the average cell-specific respiration rate apparently decreased towards the end of the time-series experiment. $\mathrm{R}$ was therefore corrected using the relationship with PA obtained $(\mathrm{R}=7.2$ $10^{-11} \mathrm{PA}^{1.87 \pm 0.17}$; Figure 3 ) to account for the observed increase in prokaryote abundance. Using this equation, we derived a value of $\mathrm{R}$ corresponding to the prokaryote assemblage representative of conditions in situ (i.e., the prokaryote abundance inside the Niskin bottles). The resulting corrected estimates of $\mathrm{R}$ averaged $0.22 \pm 0.05 \mu \mathrm{mol} \mathrm{O} \mathrm{I}^{-1} \mathrm{~d}^{-1}$ across the study area, being about 4 fold higher at $600 \mathrm{~m}(0.35 \pm$ $\left.0.08 \mu \mathrm{mol} \mathrm{O} \mathrm{O}_{2} \mathrm{1}^{-1} \mathrm{~d}^{-1}\right)$ than at $1000 \mathrm{~m}$ depth $(0.08 \pm$ $\left.0.03 \mu \mathrm{mol} \mathrm{O} \mathrm{O}_{2} \mathrm{l}^{-1} \mathrm{~d}^{-1}\right)$. These rates are about two thirds of those directly derived from the incubation of unconcentrated samples $\left(0.33 \pm 0.03 \mu \mathrm{mol} \mathrm{O} \mathrm{O}_{2} \mathrm{l}^{-1} \mathrm{~d}^{-1}\right)$, showing that the re-scaling procedure probably accounted for potential artifacts derived from growth after confinement.

[13] The derived respiration rates for the mesopelagic subtropical NE Atlantic are about one order of magnitude

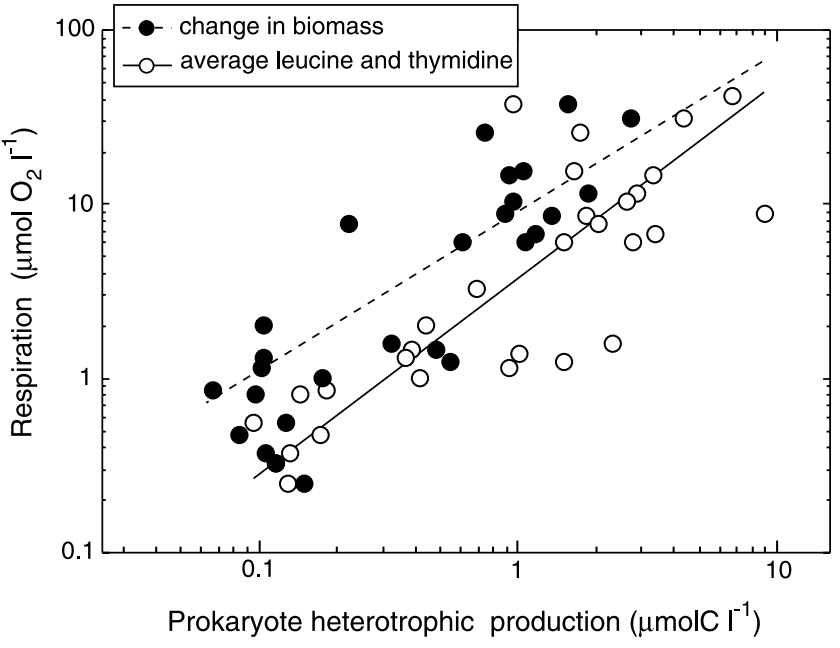

Figure 2. The relationship between integrated prokaryote respiration and integrated prokaryote production across all the experiments, with concentrated and unconcentrated water samples. The production was estimated both as the prokaryote biomass increment in respiration experiments and as the average tritiated leucine and thymidine uptake.

higher than the average global rate implied in previous assessments $\left(0.02 \mu \mathrm{mol} \mathrm{O}_{2} \mathrm{1}^{-1} \mathrm{~d}^{-1}\right)$ [Arístegui et al., 2003]. The reason for this discrepancy may be two-fold: (1) the subtropical NE Atlantic is an area with particularly high respiratory activity, as it receives substantial lateral organic inputs from the African upwelling which may fuel mesopelagic R; (2) previous estimates of the global average mesopelagic $\mathrm{R}$ may be underestimates as these were indirect ones, largely inferred from measured ETS activity and a R/ETS of 0.09, derived from senescent bacterial cultures [Packard et al., 1988; Arístegui et al., 2003]. However, the results presented here depict the mesopelagic prokaryote

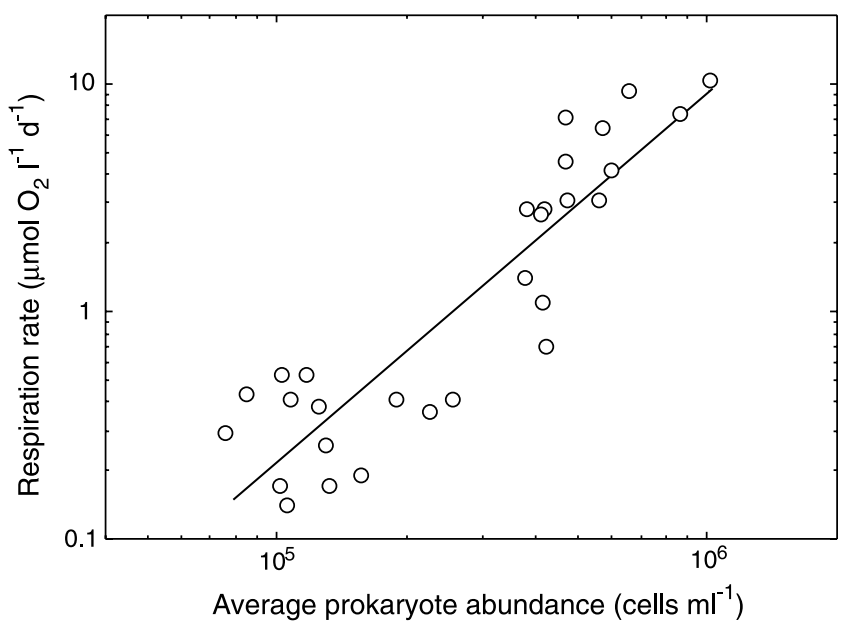

Figure 3. The relationship between prokaryote respiration rate $(\mathrm{R})$ and the average prokaryote abundance (PA) across all the experiments, with concentrated and unconcentrated water samples. PA was measured as the average value among initial and final concentrations of prokaryotes inside the experimental bottles. The solid line represents the fitted regression (Model II, reduced major axis) equation, $\mathrm{R}=$ $7.210^{-11} \mathrm{PA}^{1.87 \pm 0.17}\left(\mathrm{r}^{2}=0.76, \mathrm{p}<0.001\right)$. 
assemblages as actively growing (Table 1) rather than senescent. Indeed, the average R/ETS ratio in our data set, after excluding two data points from two coastal stations in the Cape Blanc upwelling, was 0.68 ( $\mathrm{SE} \pm 0.11$; 0,9 without excluding the two outlier points), 8 fold greater than that assumed in the past. The rather high R/ETS ratio in the mesopelagic subtropical NE Atlantic is similar to that of the mixed layer microbial assemblages [Arístegui and Montero, 1995]. More interestingly, the ratio is comparable to that (average $\mathrm{R} / \mathrm{ETS}=1.1$, range $=0.6-1.7$ ) observed during the exponential growth phase of the same bacterial cultures used to derive the R/ETS in their senescent state [Christensen et al., 1980]. Our findings suggest that the general use of a low ratio $(<0.1)$ to derive mesopelagic $\mathrm{R}$ from ETS may lead to gross underestimation of this process in the global ocean, if prokaryote assemblages are actively growing as observed in our study. Indeed, the prokaryote growth efficiency $[\mathrm{PGE}=\mathrm{P} /(\mathrm{P}+\mathrm{R})]$, estimated with the back-scaled $\mathrm{R}$ and the Leu/TdR-based $P$ was, on average, $0.18 \pm 0.03$ at $600 \mathrm{~m}$, and $0.13 \pm 0.02$ at $1000 \mathrm{~m}$. These PGE values are comparable to the average PGE of sea surface prokaryote assemblages [del Giorgio and Cole, 2000], and suggest that mesopelagic R must be comparable to that of the epipelagic zone if similar integrated abundances of prokaryotes are found in both zones, as was the case in our region of study.

[14] We further calculated integrated mesopelagic $\mathrm{R}$ in the subtropical NE Atlantic by combining 10 vertical profiles (200-1000 m) ofETS activity with the empirically-estimated $\mathrm{R}$ to ETS ratio of 0.68 , yielding an average value of $68 \pm$ $8 \mathrm{mmol} \mathrm{C} \mathrm{m} \mathrm{C}^{-2}$ (assuming a respiratory quotient, $\mathrm{RQ}=$ $0.69)$. The mesopelagic $\mathrm{R}$ is comparable to the epipelagic $\mathrm{R}$ measured during the same cruise (64-97 mmol C m ${ }^{-2} \mathrm{~d}^{-1}$ (N. Navarro, personal communication, 2004)) or in previous studies $\left(89-136 \mathrm{mmol} \mathrm{C} \mathrm{m} \mathrm{C}^{-2} \mathrm{~d}^{-1}\right)$ in the same region [Duarte et al., 2001]. This indicates a very high carbon demand by mesopelagic prokaryotes that cannot possibly be fulfilled by vertical inputs of organic carbon alone. Estimates of vertical inputs of organic carbon into the mesopelagic layer at this region are well below these values (unpublished results), and the activity of the layer must be, therefore, largely fueled by lateral exports from the highly productive NW African upwelling system.

[15] Several sets of evidence support this hypothesis. Recent studies in the NW African coast indicate that upwelling filaments may transport offshore up to $50 \%$ of coastal upwelling primary production, even during low to moderate upwelling pulses [Gabric et al., 1993; GarcíaMuñoz et al., 2004]. Upwelling filaments are known to be a widespread and recurrent phenomena in the NW African coast [Kostianoy and Zatsepin, 1996]; hence their annual contribution to the coastal-offshore exchange of organic matter must be important. Additionally, high concentrations of particulate organic carbon (POC) might be also transported to the open ocean via intermediate or deep nepheloid layers. Indeed, vertical profiles of suspended POC from the same cruise (unpublished data) show carbon concentrations 3-6 $\mu \mathrm{M}$ higher in the mesopelagic zone of the region of study compared to published results from the North Atlantic subtropical gyre. Moreover, the profiles show peaks of POC in the upper $1000 \mathrm{~m}$, more intense towards the coast, which could only be explained by lateral advection of organic matter from the African shelf.
[16] In conclusion, our findings confirm that mesopelagic prokaryote assemblages are active nodes of organic carbon remineralisations and act as major sinks for organic carbon in the subtropical NE Atlantic Ocean. A large part of the mesopelagic respiration must be supported by coastal advection of organic matter from the highly productive upwelling system to the open ocean. The possibility that the high mesopelagic $\mathrm{R}$ reported here could be a feature of other eastern boundary regions, bordering high productive upwelling systems, awaits verification. If confirmed, the overall organic carbon sink in these regions would play a key role in the global carbon cycle in the oceans.

[17] Acknowledgments. This research is part of the COCA project, funded by the Spanish Plan Nacional de I+D (REN2000 1471-CO2-O1MAR). LA and JMG were also supported by projects MICRODIFF (REN2001-2120/MAR) and DEBACOCA (REN2001-4211-E). Hugh Ducklow, Peter LeB. Williams and one anonymous reviewer provided valuable comments, which helped improving the manuscript.

\section{References}

Arístegui, J., and M. F. Montero (1995), The relationship between community respiration and ETS activity in the ocean, J. Plankton Res., 17, $1563-1571$

Arístegui, J., S. Agustí, and C. M. Duarte (2003), Respiration in the dark ocean, Geophys. Res. Lett., 30(2), 1041, doi:10.1029/2002GL016227.

Cho, B. C., and F. Azam (1988), Major role of bacteria in biogeochemical fluxes in the ocean's interior, Nature, 332, 441-443.

Christensen, J. P., T. G. Owens, A. H. Devol, and T. T. Packard (1980), Respiration and physiological state in marine bacteria, Mar. Biol., 55, $267-276$

del Giorgio, P. A., and J. J. Cole (2000), Bacterial energetics and growth efficiency, in Microbial Ecology of the Oceans, edited by D. L. Kirchman, pp. 289-326, John Wiley, Hoboken, N. J.

del Giorgio, P. A., and C. M. Duarte (2002), Respiration in the open ocean, Nature, 420, 379-384.

Duarte, C. M., S. Agustí, J. Arístegui, N. González, and R. Anadón (2001), Evidence for a heterotrophic subtropical northeast Atlantic, Limnol. Oceanogr., 46, 425-428.

Gabric, A. J., L. García, L. van Camp, L. Nykjaer, W. Eifler, and W. Schrimpf (1993), Offshore export of shelf production in the Cape Blanc (Mauritania) giant filament as derived from coastal zone color scanner imagery, J. Geophys. Res., 98, 4697-4712.

García-Muñoz, M., J. Arístegui, M. F. Montero, and E. D. Barton (2004), Distribution and transport of organic matter along a filament-eddy system in the Canaries-NW Africa coastal transition zone region, Prog. Oceanogr., 62, 115-129.

Gasol, J. M., and P. A. del Giorgio (2000), Using flow cytometry for counting natural planktonic bacteria and understanding the structure of planktonic bacterial communities, Sci. Mar., 64, 197-224.

Jenkins, W. J. (1977), Tritium-helium dating in the Sargasso Sea: A measurement of oxygen utilization rates, Science, 196, 291-292.

Jenkins, W. J. (1982), Oxygen utilization rates in the North Atlantic Subtropical Gyre and primary production in oligotrophic systems, Nature, $300,246-248$

Kostianoy, A. G., and A. G. Zatsepin (1996), The West African coastal upwelling filaments and cross-frontal water exchange conditioned by them, J. Mar. Syst., 7, 349-359.

Norland, S. (1993), The relationship between biomass and volume of bacteria, in Handbook of Methods in Aquatic Microbial Ecology, edited by P. F. Kemp et al., pp. 303-307, Lewis, Boca Raton, Fla.

Packard, T. T., M. Denis, M. Rodier, and P. Garfield (1988), Deep-ocean metabolic $\mathrm{CO}_{2}$ production: Calculations from ETS activity, Deep Sea Res., Part I, 35, 371-382.

J. Arístegui, Departamento de Biología, Universidad de las Palmas de Gran Canaria, Las Palmas de Gran Canaria, E-35017 Las Palmas de Gran Canaria, Islas Canarias, Spain. (jaristegui@dbio.ulpgc.es)

L. Alonso-Sáez and J. M. Gasol, Departament de Biologia Marina i Oceanografia, Institut de Ciències del Mar-CMIMA, CSIC, Pg Marítim de la Barceloneta 37-49, E-08003 Barcelona, Catalunya, Spain.

C. M. Duarte, IMEDEA, CSIC-UiB, C/Miquel Marques 21, E-07190 Esporles, Islas Baleares, Spain. 